\title{
Synthesis of Polyamide 6-block-Vinyl Polymers Using New Polyamide 6 Radical Initiators
}

\author{
Tetsuji Hirano, ${ }^{*}$ Ryotaro Amano, Takamasa Fujil, ${ }^{*}$ Kenjiro Onimura, \\ Hiromori TsuTsumI, and Tsutomu OISHI ${ }^{\dagger}$
}

Faculty of Engineering, Yamaguchi University, 2557 Tokiwadai, Ube,

Yamaguchi 755-8611, Japan

* Polymer Laboratory, Ube Industries, Ltd., 1-12-32 Nishihonmachi, Ube,

Yamaguchi 755-8633, Japan

(Received March 11, 1999)

\begin{abstract}
Two polyamide 6 (PA6) radical initiators (PA6ini), AI and AIA types (A : PA6 segment, I : azo group), were prepared from 4,4'-azobis-2-cyanopentanoyl chloride and PA6 prepolymers having controlled average molecular weights. Various PA6-block-vinyl polymers were synthesized by radical polymerizations of vinyl monomers, such as styrene, methyl methacrylate (MMA), butyl methacrylate, hydroxyethyl methacrylate and vinyl acetate (VAc) using PA6inis. The polymerizations of MMA proceeded homogeneously in phenol/methanol $\left(4_{\mathrm{vol}} / \mathrm{l}_{\mathrm{vol}}\right)$, formic acid and $2,2,2$-trifluoroethanol. The overall initiation efficiency of PA6ini (AI type) was 0.11 for the polymerization of MMA in formic acid at $60^{\circ} \mathrm{C}$ for $24 \mathrm{~h}$. Poly(MMA) in the polymer synthesized using PA6ini was dependent on concentration, molecular weight and type of PA6ini. PA6-block-poly(VAc) was synthesized in 2,2,2-trifluoroethanol (TFE), but not in phenol/methanol $\left(4_{\mathrm{vol}} / 1_{\mathrm{vol}}\right)$.

KEY WORDS Polyamide 6 Radical Initiator / Macroazoinitiator / Block Copolymer / Radical Polymerization / Vinyl Monomers /
\end{abstract}

Polyamide 6 (PA6) has many industrial applications. Block copolymers from PA6 and other polymers, such as vinyl polymers, polyethers, polyimides and polyesters, were synthesized, expecting new properties. ${ }^{1}$ However, there have been few studies on synthesis and characterization of block copolymers of PA6 with vinyl polymers except poly(styrene) $(\mathrm{St})^{2-7}$ and rubbers such as poly(butadiene-acrylonitrile), ${ }^{8-11}$ poly(St-butadiene), ${ }^{12,13}$ poly(butadiene) ${ }^{6,14-16}$ and poly(isobutylene). ${ }^{17}$ Melt polymerizations are often applied to the synthesis of block copolymers with PA6. ${ }^{1}$ One problem is required thermal stability of vinyl polymer components. If block copolymerizations are carried out under mild conditions, new block copolymers having unique properties should be obtained.

Polymeric radical initiators, such as macroperoxyinitiators and macroazo-initiators (MAI), are useful for preparation of block copolymers because they make it possible to copolymerize a wide variety of vinyl monomers under mild conditions. ${ }^{18}$ In these studies, polymeric radical initiators consisting of polyamides were mainly MAIs. In unique cases, Craubner studied the synthesis of block copolymers with partially nitrosated polyamides, such as PA6, polyamide 66 (PA66), polyamide 610 (PA610) and poly[imino(4,4'-bisphenylenemethylene)imino-1,10-dioxo-decamethylene ]. ${ }^{19,20}$ But, detailed studies on MAIs of polyamide from aminocarboxylic acid or lactam have been scarcely reported, except those of Craubner's.

4,4'-Azobis-4-cyanopentanonic acid (ACPA) and 4,4'azobis-4-cyanopentanoyl chloride (ACPC) have been used for synthesis of various MAIs. ${ }^{18,21,22}$ Ueda et al. synthesized MAIs consisting of PA66 or PA610 and block copolymers from these MAIs and St. ${ }^{23-25}$ These MAIs were prepared by the interfacial polycondensation in

\footnotetext{
† To whom all correspondence should be addressed.
}

the presence of ACPC, and had many azo groups in per polymer chain. MAIs of polyamide obtained from aminocarboxylic acid or lactam, however, cannot be synthesized by interfacial polycondensation.

In this study, novel PA6inis, AI and AIA type (A, PA6 segment; I, azo group), were prepared by the condensation of ACPC and PA6 prepolymers having various molecular weights. These PA6inis have only one azo group per polymer chain, and the length of PA6 segments in the block copolymer prepared with PA6ini will be easily controlled by used PA6 prepolymers. Block copolymers of PA6 and various vinyl polymers, such as poly(methyl methacrylate), poly(St), poly(butyl methacrylate), poly(hydroxyethyl methacrylate), and poly(vinyl acetate), were synthesized using PA6ini.

\section{EXPERIMENTAL}

\section{Materials}

$\varepsilon$-Caprolactam (CL) (Ube Ind., Ltd.) was a commercial-grade. Vinyl monomers, such as St, methyl methacrylate (MMA), butyl methacrylate (BMA), hydroxyethyl methacrylate (HEMA), and vinyl acetate (VAc) (Wako Pure Chemical Co.) were distilled just before use. ${ }^{26}$ Phenol, benzene, methanol, $m$-cresol, formic acid, 2,2,2-trifluoroethanol (TFE), 1,3-dimethyl-2-imidazolidinone (DMI), and $\mathrm{LiCl}$ as extra pure grades of Kishida Chemical Co. were used without further purification. 1,1,1,3,3,3-Hexafluoro-2-propanol (HFIP) (Central Glass Co.) and tetrahydrofuran (THF) (Wako Pure Chemical Co.) were distilled before used. ACPA (Aldrich) was recrystallized twice from methanol. ACPC was prepared according to Ueda et al. ${ }^{23}$

\section{Polymerization}

PA6 Prepolymer. PA6 prepolymers were obtained by the hydrolytic polymerization of $\mathrm{CL}$ in the presence of 


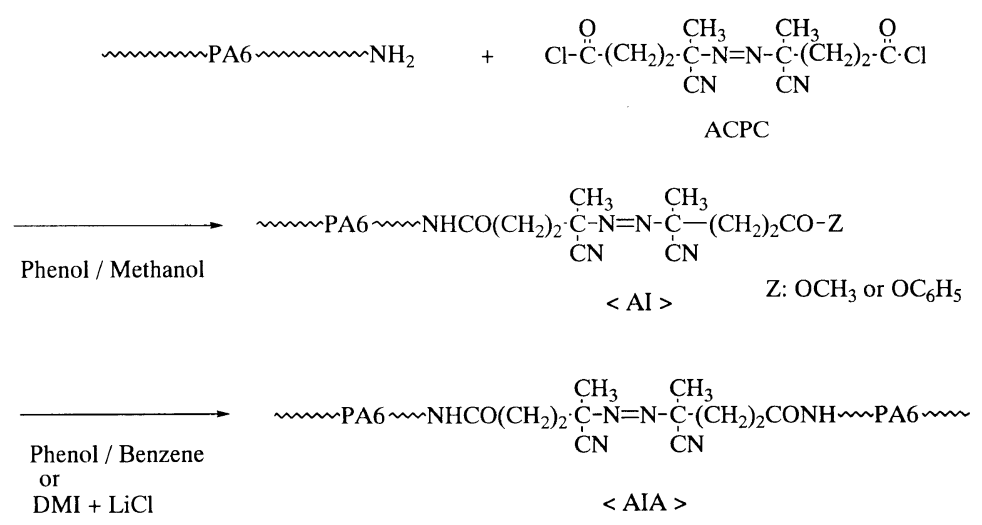

Scheme 1. Syntheses of AI type (1) and AIA type (2) polyamide 6 radical initiators.

stearylamine (SA) as terminator. CL, water and SA were heated in a stainless steel reactor under nitrogen atmosphere at $250^{\circ} \mathrm{C}$. PA6 was washed with methanol by a Soxhlet apparatus for each $20 \mathrm{~h}$ and dried under reduced pressure at $60^{\circ} \mathrm{C}$ for 1 day.

PA6ini. PA6 prepolymer was dissolved in phenol/ methanol $\left(4_{\mathrm{vol}} / 1_{\mathrm{vol}}\right)$ at r.t. or DMI (containing $10 \mathrm{wt} \%$ $\mathrm{LiCl})$ at $60^{\circ} \mathrm{C}$. A solution of ACPC in THF was added to the solution cooled at $5^{\circ} \mathrm{C}$ with vigorous stirring. The reaction was carried out under various conditions. The solution was poured into an excess amount of methanol to precipitate PA6ini, which was filtered, washed with methanol 3 times, and dried under reduced pressure at r.t. for 1 day.

PA6-block-Vinyl Polymer. PA6ini and a vinyl monomer were dissolved in a solvent at r.t. The solution was stirred at $60^{\circ} \mathrm{C}$ for $24 \mathrm{~h}$. The solution was poured into excess methanol to precipitate crude PA6-block-vinyl polymer, which was filtered, washed with methanol 3 times, and dried under reduced pressure at r.t. for 1 day. The product was washed with chloroform by a Soxhlet apparatus for $20 \mathrm{~h}$ to remove the vinyl homopolymer. The product was dried under reduced pressure at r.t. for 1 day.

\section{Measurements}

${ }^{1} H$ NMR, IR, UV, End Group and Solution Viscosity. ${ }^{1} \mathrm{H}$ NMR spectra were measured in $\mathrm{D}_{2} \mathrm{SO}_{4}(97 \%)$ at r.t. using tetramethylsilane (TMS) as internal standard with a JEOL JNM-EX400WB FT-NMR (400 MHz) spectrometer or JEOL EX270.

IR spectra of PA6-block-poly(St) were measured using a Shimadzu FT IR-8100A.

UV spectra for PA6inis and ACPA in formic acid $\left(5 \mathrm{~mol} \mathrm{dL}^{-1}\right)$ at r.t. were measured with a Spectro Multi Channel Photo Detector MCPD-1000 (Otsuka Electronics Co., Ltd.).

The concentrations of amino groups at the chain ends of PA6 and PA6ini were measured by titration in phenol/ methanol $\left(9_{\mathrm{vol}} / 1_{\mathrm{vol}}\right)$ with $0.05 \mathrm{~N}$ sodium hydroxide at r.t.

Reduced viscosities $\left(\eta_{\text {red }}\right)$ of $0.5 \mathrm{~g} \mathrm{dL}^{-1}$ PA6 and PA6ini solutions were measured in $m$-cresol at $25^{\circ} \mathrm{C}$ with an Ostwald viscometer.

Molecular Weights. Molecular weights of PA6-blockpoly(MMA), poly(MMA) segment, and poly(VAc) were measured by GPC. PA6-block-poly(MMA) was dissolv- ed in HFIP (containing $5 \mathrm{mM} \mathrm{CF} \mathrm{CO}_{3} \mathrm{COONa}$ ) and GPC was carried out with Tosoh HLC-8020 and columns of Shodex HFIP-806M $\times 2$ (Showa Denko K.K.); column temperature $=38^{\circ} \mathrm{C}$, flow rate $=1.0 \mathrm{~mL} \mathrm{~min}^{-1}$. Molecular weight was calibrated with poly(MMA) standards.

A sample for estimating molecular weight of the poly(MMA) segment was prepared as follows. PA6block-poly(MMA) (30 mg) and 48\% hydrobromic acid $(5 \mathrm{~mL})$ were heated in a sealed glass tube at $120^{\circ} \mathrm{C}$ for $24 \mathrm{~h}$. The insoluble parts were collected by filtration and dried under reduced pressure at r.t. for 1 day. The solids, methanol $(0.5 \mathrm{~mL})$ and benzene $(5 \mathrm{~mL})$ were mixed, and 2.0 M (trimethylsilyl)diazomethane in hexane (Aldrich) $(0.2 \mathrm{~mL})$ was added to it. The solution was stirred at r.t. for 1 day. After the solution became homogeneous, a solution of acetic acid $(2.0 \mathrm{M})$ in benzene $(0.2 \mathrm{~mL})$ was added and stirred at r.t. for $1 \mathrm{~h}$. The sample was obtained by evaporation of the solution. GPC was achieved with Shimadzu Class-LC10, RID-10A, and LC-10A pump with columns of Shodex $80 \mathrm{M} \times 2$ (Showa Denko K.K.); column temperature $=40^{\circ} \mathrm{C}$, flow rate $=1.0 \mathrm{~mL}$ $\min ^{-1}$. THF was used as solvent. Molecular weight was calibrated with poly(MMA) standards.

GPC of poly(VAc) was carried out by Shimadzu Chromatopac C-E4A, SPD-10A UV detector and LC$10 \mathrm{~A}$ pump with columns of $\mathrm{HSG}-10 \mathrm{H}, 15 \mathrm{H}, 20 \mathrm{H}$, and $40 \mathrm{H}$. THF was used as solvent; column temperature $=$ $50^{\circ} \mathrm{C}$ and flow rate $=0.8 \mathrm{~mL} \mathrm{~min}{ }^{-1}$. The molecular weight was calibrated with poly $(\mathrm{St})$ standards.

Number-average molecular weight $\left(M_{n}\right)$ of PA6 was calculated from the concentration of amino groups.

\section{RESULTS AND DISCUSSION}

\section{Synthesis of PA6ini}

According to Scheme 1, PA6inis, AI, and AIA, were synthesized by the condensation of PA6 prepolymer and ACPC. Since reacted PA6 segments have no amino groups, the mole fraction of reacted PA6 segments, $P_{\mathrm{N} 6}$, was calculated as,

$$
P_{\mathrm{N} 6}=1-\frac{\left[\mathrm{NH}_{2}\right]}{\left[\mathrm{NH}_{2}\right]_{0}}
$$

where $\left[\mathrm{NH}_{2}\right]$ and $\left[\mathrm{NH}_{2}\right]_{0}$ are the concentrations of amino groups after and before the reaction, respectively. 
Table I. Synthesis of AI type PA6 radical initiators with ACPC

\begin{tabular}{|c|c|c|c|c|c|c|c|c|}
\hline \multirow{3}{*}{ Run } & \multicolumn{2}{|c|}{ Original PA6 } & \multirow{3}{*}[\mathrm{ACPC}]{$/[\mathrm{PA} 6]$} & \multirow{3}{*}{$\frac{\text { Time }}{\mathrm{h}}$} & \multirow{3}{*}{$\frac{\text { Temp }}{{ }^{\circ} \mathrm{C}}$} & \multicolumn{3}{|c|}{ Resulting } \\
\hline & \multirow{2}{*}{$M_{n} \times 10^{-3}$} & \multirow{2}{*}{$\frac{\eta_{\text {red }}{ }^{\mathrm{b}}}{\mathrm{dL} \mathrm{g}^{-1}}$} & & & & \multirow{2}{*}{$\begin{array}{c}\text { Yield } \\
\mathrm{wt} \%\end{array}$} & \multirow{2}{*}{$P_{\mathrm{N} 6}{ }^{\mathrm{c}}$} & \multirow{2}{*}{$\frac{\eta_{\text {red }}{ }^{\mathrm{b}}}{\mathrm{dLg} \mathrm{g}^{-1}}$} \\
\hline & & & & & & & & \\
\hline I1 & 5 & 0.50 & 3.0 & 40.0 & 5 & 89.2 & 1.0 & 0.51 \\
\hline I2 & 6 & 0.60 & 2.7 & 40.0 & 5 & 82.3 & 1.0 & 0.65 \\
\hline I3 & 8 & 0.79 & 3.0 & 40.0 & 5 & 96.8 & 1.0 & 0.81 \\
\hline I4 & 13 & 1.10 & 3.0 & 40.0 & 5 & 91.3 & 1.0 & 1.15 \\
\hline$I 5^{\mathrm{d}}$ & 5 & 0.50 & 2.7 & 1.5 & 25 & 91.0 & 1.0 & 0.48 \\
\hline $16^{d}$ & 13 & 1.10 & 2.7 & 3.0 & 20 & 83.0 & 1.0 & 1.18 \\
\hline
\end{tabular}

${ }^{a}$ Reacted in phenol/methanol $\left(4_{\text {vol }} / 1_{\text {vol }}\right) . \quad{ }^{\mathrm{b}}$ Measured by Ostwald viscometer in $m$-cresol at $25^{\circ} \mathrm{C}, c=0.5 \mathrm{~g} \mathrm{dL}^{-1} . \quad{ }^{\mathrm{c}}$ Mole fraction of reacted PA6 segments. ${ }^{\mathrm{d}}$ Mixture was stirred at $5^{\circ} \mathrm{C}$ for $30 \mathrm{~min}$ before the reaction.

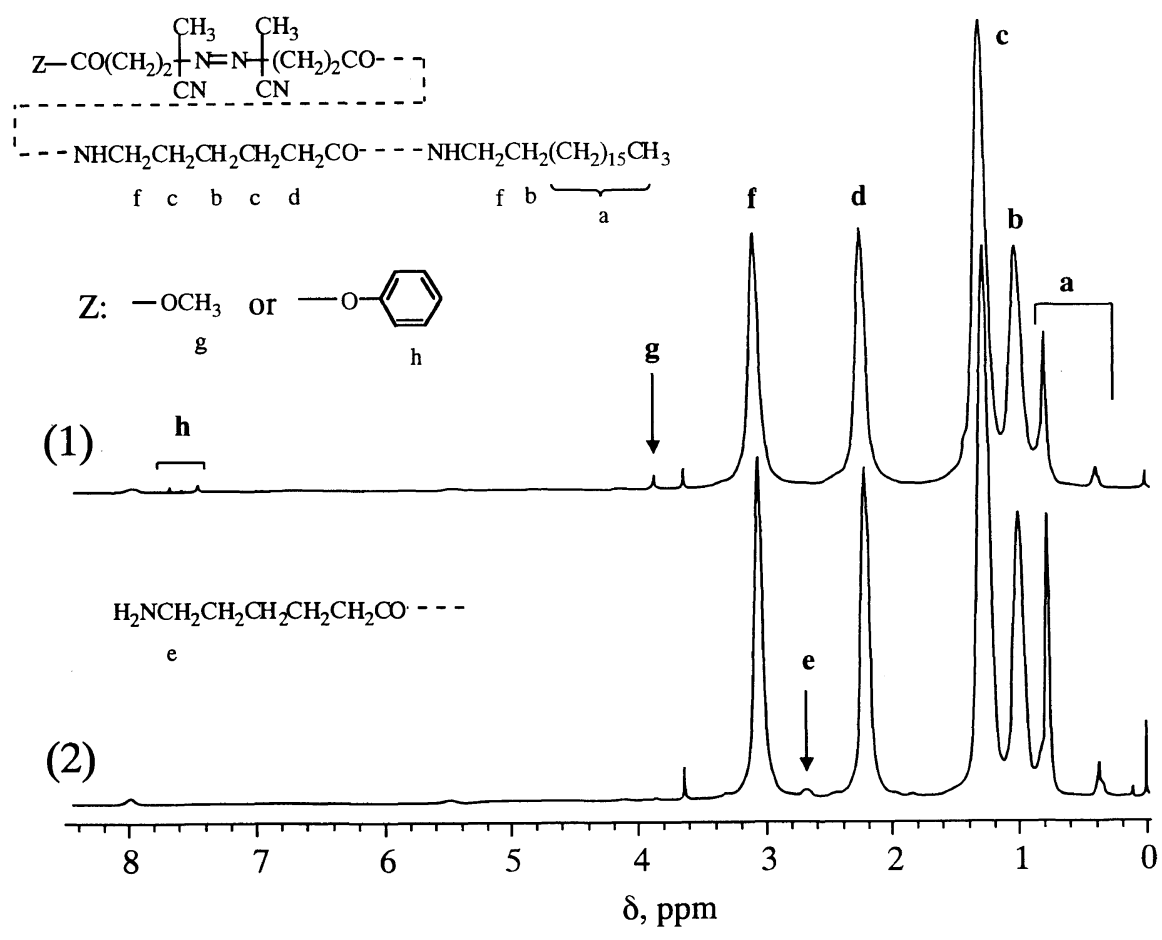

Figure 1. ${ }^{1} \mathrm{H}$ NMR spectra of PA6ini (Run I1) (1) and original PA6 prepolymer (2) in $\mathrm{D}_{2} \mathrm{SO}_{4}$.

The usable solvents for synthesis of PA6inis were limited since PA6 dissolves only in few solvents. Seo et al. synthesized PMMA-graft-PA6 oligomers by condensation reaction between the acid chloride groups of poly(MMA)-co-poly(methacryloyl chloride) and the amino groups of PA6 oligomer in phenol. ${ }^{27}$ In this study, synthesis of AI type was done in phenol/methanol $\left(4_{\mathrm{vol}} / 1_{\mathrm{vol}}\right)$ and the results are summarized in Table I. Most amino groups were reacted at $5^{\circ} \mathrm{C}$ for $40 \mathrm{~h}$ (Run I1-I4) and $P_{\mathrm{N} 6}$ s were 1.0. Figure 1 shows ${ }^{1} \mathrm{H}$ NMR spectra of PA6ini and original PA6 prepolymer. The signal (e) at $2.69 \mathrm{ppm}$, assigned to methylene protons of PA6 segments adjacent to amino groups, was not observed in ${ }^{1} \mathrm{H}$ NMR spectrum of PA6ini. Acid chloride groups of ACPC thus preferentially react with amino groups of PA6 prepolymers rather than with large amounts of hydroxyl groups of phenol and methanol. The signals of methyl protons due to methoxy groups and aromatic hydrogens due to phenoxy groups were observed at $3.9 \mathrm{ppm}$ and $7.4-7.7 \mathrm{ppm}$, respectively. These signals remained after purification by reprecipitation from the
TFE solution into excess methanol. Excess acid chloride groups, remaining unreacted with amino groups, may thus react with phenol and methanol.

Solution viscosity, $\eta_{\text {red }}$, of PA6inis (Run I1-I4) little changed before and after the reaction. Thus, the molecular weights of PA6inis were almost the same as original PA6 homopolymers.

UV spectra of PA6ini (Run I1), ACPA, and original PA6 measured in formic acid are shown in Figure 2. Absorption based on azo groups was observed at 300 $400 \mathrm{~nm}$ in the solution of PA6ini (Run I1). The area of absorption due to PA6ini was almost the same as that of ACPA when solutions with similar concentrations to that of azo group were prepared. This indicates that PA6inis could be obtained without significant decomposition of azo groups during the condensation reaction. Several MAIs were prepared at room temperature and above. ${ }^{18}$ Laverty et al. synthesized MAIs from poly(ethylene oxide) and ACPC at $35^{\circ} \mathrm{C} .{ }^{28}$ When the reactions were performed at higher temperature, $P_{\mathrm{N} 6}$ s for $1.5 \mathrm{~h}$ at $25^{\circ} \mathrm{C}$ (Run I5) and $3 \mathrm{~h}$ at $20^{\circ} \mathrm{C}$ 


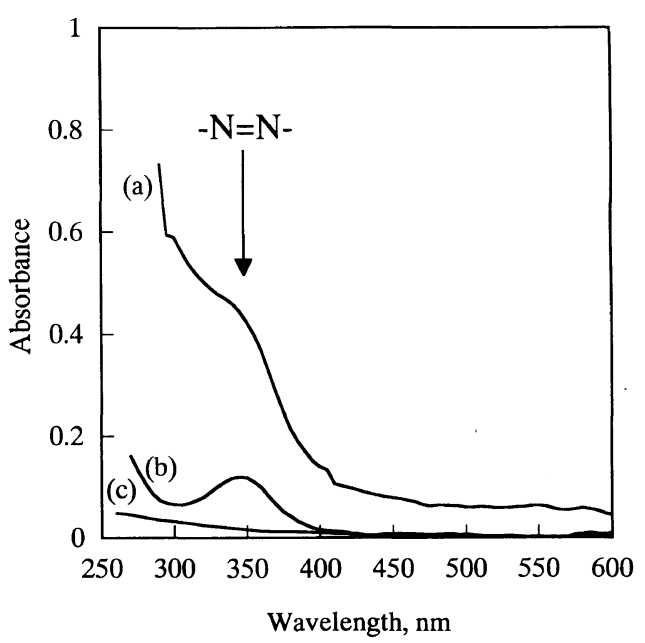

Figure 2. UV spectra of PA6ini (Run I1) (a), ACPA (b) and original PA6 prepolymer (c) in formic acid.
(Run I6) were both 1.0. It was confirmed by UV spectra that no significant decomposition of azo groups occurred.

The results of synthesis of AIA type are summarized in Table II. $P_{\mathrm{N} 6}$ was 0.5 when PA6ini was synthesized from PA6 prepolymer $\left(M_{n}=5 \times 10^{3}\right)$ in phenol/benzene $\left(4_{\mathrm{vol}} / 1_{\mathrm{vol}}\right)$ at $5^{\circ} \mathrm{C}$ for $48 \mathrm{~h}$. The rate of condensation in DMI is expected higher than that in phenol/benzene because DMI is a basic solvent. ${ }^{29}$ In DMI (containing $10 \mathrm{wt} \% \mathrm{LiCl}$ ) at $5^{\circ} \mathrm{C}$ for $48 \mathrm{~h}, P_{\mathrm{N} 6}$ was 0.8 (Run I9). To complete the condensation, the temperature was raised to $20^{\circ} \mathrm{C}$. $P_{\mathrm{N} 6}$ reached 1.0 in both cases of at $5 \mathrm{~h}$ in phenol/benzene $\left(4_{\mathrm{vol}} / 1_{\mathrm{vol}}\right)$ (Run I8) and for $0.2 \mathrm{~h}$ in DMI (containing $10 \mathrm{wt} \% \mathrm{LiCl}$ ) (Run I10), as shown in Table II. The relationship between $M_{n}$ and $\eta_{\text {red }}$ of PA6 is expressed by

$$
\eta_{\text {red }}=3.08 \times 10^{-4} \cdot M_{n}^{0.87}
$$

between $M_{n}=4 \times 10^{3}$ and $30 \times 10^{3} \cdot{ }^{30} \eta_{\mathrm{red}}$ s of PA6 whose $M_{n}$ are $10 \times 10^{3}$ and $16 \times 10^{3}$ were calculated as 0.93 and 1.40 by eq 2 , respectively. $\eta_{\text {red }}$ of PA6inis (Run I8 and

Table II. Synthesis of AIA type PA6 radical initiators with ACPC

\begin{tabular}{|c|c|c|c|c|c|c|c|c|c|}
\hline \multirow{3}{*}{ Run } & \multicolumn{2}{|c|}{ Original PA6 } & \multirow{3}{*}[\mathrm{ACPC}]{$/[\mathrm{PA} 6]$} & \multirow{3}{*}{ Solvent ${ }^{b}$} & \multirow{3}{*}{$\frac{\text { Time }}{\mathrm{h}}$} & \multirow{3}{*}{$\frac{\text { Temp }}{{ }^{\circ} \mathrm{C}}$} & \multicolumn{3}{|c|}{ Resulting } \\
\hline & \multirow{2}{*}{$M_{n} \times 10^{-3}$} & \multirow{2}{*}{$\frac{\eta_{\text {red }^{\mathrm{a}}}}{\mathrm{dLg}^{-1}}$} & & & & & \multirow{2}{*}{$\frac{\text { Yield }}{\text { wt } \%}$} & \multirow{2}{*}{$P_{\mathrm{N} 6}{ }^{\mathrm{c}}$} & \multirow{2}{*}{$\frac{\eta_{\text {red }}^{\mathrm{a}}}{\mathrm{dLg}^{-1}}$} \\
\hline & & & & & & & & & \\
\hline 17 & 5 & 0.50 & 0.51 & $\mathrm{PhOH} / \mathrm{Bz}$ & 48.0 & 5 & 90.4 & 0.5 & 0.68 \\
\hline $18^{\mathrm{d}}$ & 5 & 0.50 & 0.50 & $\mathrm{PhOH} / \mathrm{Bz}$ & 5.0 & 20 & 92.0 & 1.0 & 0.86 \\
\hline 19 & 5 & 0.50 & 0.51 & $\mathrm{DMI}(+\mathrm{LiCl})$ & 48.0 & 5 & 83.2 & 0.8 & 0.73 \\
\hline $\mathrm{I} 10^{\mathrm{d}}$ & 5 & 0.50 & 0.52 & DMI $(+\mathrm{LiCl})$ & 0.2 & 20 & 95.0 & 1.0 & 0.85 \\
\hline $111^{\mathrm{d}}$ & 8 & 0.70 & 0.50 & $\mathrm{DMI}(+\mathrm{LiCl})$ & 0.5 & 20 & & 1.0 & \\
\hline $\mathrm{I} 12^{\mathrm{d}}$ & 8 & 0.70 & 0.50 & DMI $(+\mathrm{LiCl})$ & 1.0 & 20 & 93.3 & 1.0 & 1.21 \\
\hline $113^{\mathrm{d}}$ & 13 & 1.10 & 0.50 & $\mathrm{DMI}(+\mathrm{LiCl})$ & 0.5 & 20 & & 0.9 & \\
\hline $\mathrm{I} 14^{\mathrm{d}}$ & 13 & 1.10 & 0.50 & DMI $(+\mathrm{LiCl})$ & 1.0 & 20 & & 1.0 & \\
\hline
\end{tabular}

${ }^{a}$ Measured by Ostwald viscometer in $m$-cresol at $25^{\circ} \mathrm{C}, c=0.5 \mathrm{gdL}^{-1} .{ }^{\mathrm{b}} \mathrm{PhOH} / \mathrm{Bz}$, phenol $/$ benzene $\left(4_{\mathrm{vol}} / 1_{\mathrm{vol}}\right) ; 10 \mathrm{wt} \% \mathrm{LiCl}$ in $\mathrm{DMI}$ (1,3-dimetyl-2-imidazolidinone). ${ }^{\mathrm{c}}$ Mole fraction of reacted PA6 segments. ${ }^{\mathrm{d}}$ Mixture was stirred at $5^{\circ} \mathrm{C}$ for 30 min before the reaction.

Table III. Polymerization of MMA with PA6 radical initiator at $60^{\circ} \mathrm{C}^{\mathrm{a}}$

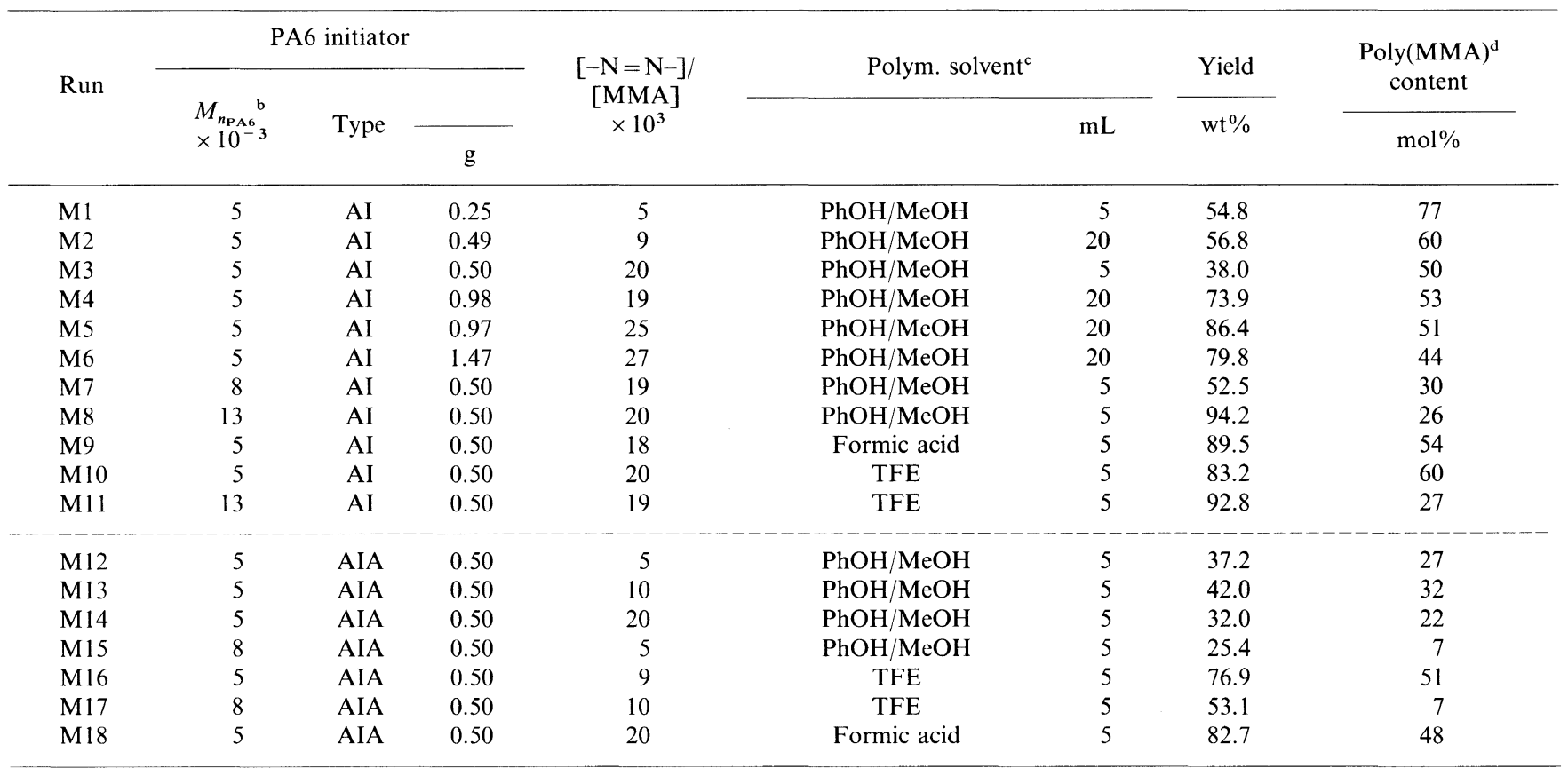

${ }^{a}$ Polymerization time, $24 \mathrm{~h} . \quad{ }^{\mathrm{b}} M_{n}$ of original PA6. ${ }^{\mathrm{c}} \mathrm{PhOH} / \mathrm{MeOH}$, phenol/methanol $\left(4_{\mathrm{vol}} / 1_{\mathrm{vol}}\right) ;$ TFE, 2,2,2-trifluoroethanol. ${ }^{\mathrm{d}}$ Amount of poly(MMA) in the product. Calculated from ${ }^{1} \mathrm{H}$ NMR data (solvent: $\mathrm{D}_{2} \mathrm{SO}_{4}$ ). 
I12), whose $M_{n}$ were expected to be $10 \times 10^{3}$ and $16 \times 10^{3}$, were close to the above values, as shown in Table II. This indicates that the PA6inis are AIA.

Inoue et al. reported that the average degree of condensation of MAIs based on ACPC and $\alpha, \omega$-bis(3aminopropyldimethy)polysiloxane decreased with an increase of siloxane chain lengths. ${ }^{31}$ In this study, the rate of condensation appeared to decrease with increase of $M_{n}$ of PA6 prepolymer since the $P_{\mathrm{N} 6}$ of PA6ini (Run I13) obtained from the prepolymer, whose $M_{n}$ was $13 \times 10^{3}$, was 0.9 for $0.5 \mathrm{~h}$ at $20^{\circ} \mathrm{C}$, compared to that of PA6inis with lower molecular weight (Run I10 and I11). This may result from the fact that the condensation reaction hardly took place due to relatively low concentrations of both amino and acid chloride groups, as well as the results of Inoue et al. ${ }^{31}$

\section{Synthesis of PA6-block-Vinyl Polymer}

PA6-block-PMMA. The results of the polymerizations of MMA with PA6inis are listed in Table III. The reactions were carried out at $60^{\circ} \mathrm{C}$ for $24 \mathrm{~h}$ on a reference. ${ }^{24}$ Ueda et al. reported that MAIs of PA66 and PA610 precipitated from the $m$-cresol solutions by an addition of various vinyl monomers, except St. ${ }^{24}$ No PA6inis precipitated from the solutions, such as phenol/methanol $\left(4_{\mathrm{vol}} / 1_{\mathrm{vol}}\right)$, formic acid and TFE, by an addition of MMA. The radical polymerization of MMA proceeded homogeneously. Figure 3 (a) shows ${ }^{1} \mathrm{H}$ NMR spectrum of PA6-block-poly(MMA) (Run M3). Signals based on PA6 and poly(MMA) were observed.

Hydrolysis of PA6-block-poly(MMA) was done to estimate the molecular weights of poly(MMA) segments. Figure 4 (a) shows IR spectrum of the product, which was poly(methacrylic acid) (poly(MA)) obtained by the hydrolysis of poly(MMA) segments. A sample (poly(MMA)) used for GPC, therefore, was prepared by esterification of the poly(MA) with (trimethylsilyl)diazomethane. ${ }^{32}$ It was confirmed by the IR spectrum that the product was poly(MMA), as shown in Figure 4 (b)

Figure 5 shows GPC curves of PA6-block-poly(MMA) (Run M9), PA6ini (AI type, $M_{n}=5 \times 10^{3}$ ) and poly(MMA) segments. The GPC curve of PA6-block-poly(MMA) (Run M9) showed two peaks. One coincided with the GPC curve of PA6ini and another one was close to that of poly(MMA) segments. This suggests that the product is a mixture of PA6-block-poly(MMA) and PA6 homopolymer which cannot initiate the polymerization of MMA, and the initiation efficiency of PA6ini is not $100 \%$, as also for several MAIs reported. ${ }^{18}$

The block copolymers formed from vinyl monomer and PA6ini (AI type) are shown in Scheme 2 when it is assumed that initiation efficiency is $100 \%$ and chain transfer reactions are negligible. If recombination reactions are not dependent on molecular chain or chain length, the ratio of $(\mathrm{A})$ and $(\mathrm{B})$ type in Scheme 2 may be $1: 2$. The total number of block copolymer chains, $N_{\mathrm{P}}$, obtained from PA6ini is calculated as,

$$
N_{\mathbf{P}}=(3+p) \frac{L_{1}}{4}
$$

where $L_{1}$ is the number of initial PA6ini chains and $p$ is a fraction of chains terminated by the disproportionation.

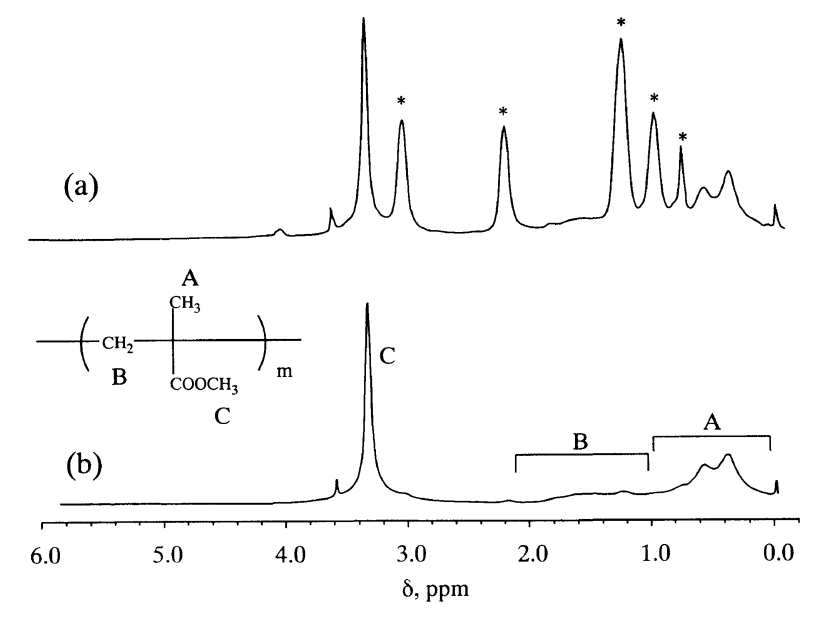

Figure 3. ${ }^{1} \mathrm{H}$ NMR spectra of PA 6-block-poly(MMA) (Run M3) (a) and poly(MMA) (b) in $\mathrm{D}_{2} \mathrm{SO}_{4} \cdot(*)$; Signals based on PA6 segment.

(a)

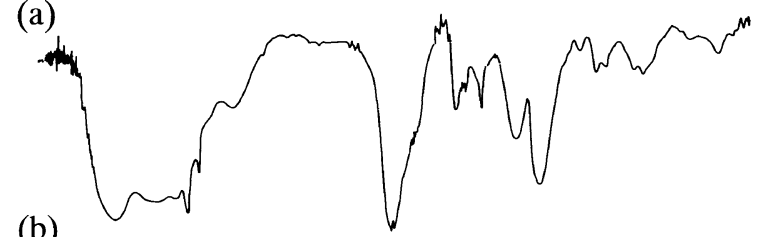

(b)

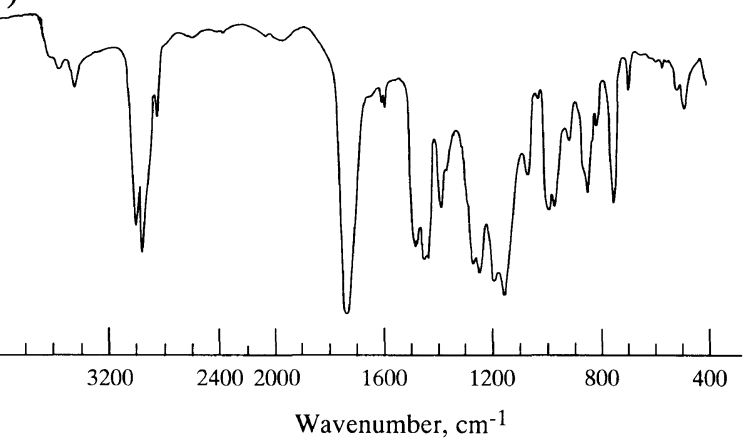

Figure 4. IR spectra of poly(MA) (a) and poly(MMA) (b). Poly(MA) was prepared by hydrolysis of PA6-block-poly(MMA) (Run M9) and poly(MMA) was obtained by esterification of poly(MA).

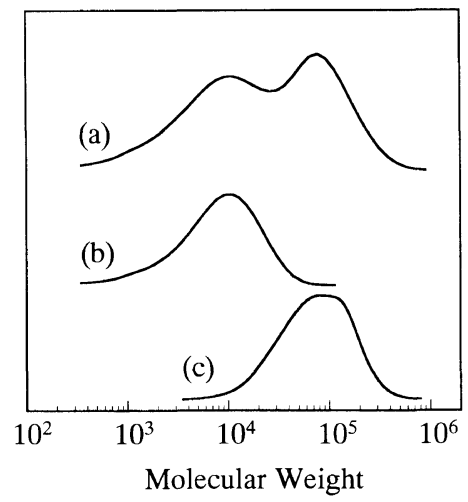

Figure 5. GPC curves of PA6-block-poly(MMA) (Run M9) (a), PA6ini (Run I1) (b), and poly(MMA) (c). Poly(MMA) was prepared by hydrolysis of PA6-block-poly(MMA) (Run M9) and esterification of resulting poly(MA). Molecular weights were calibrated with poly(MMA) standard. 


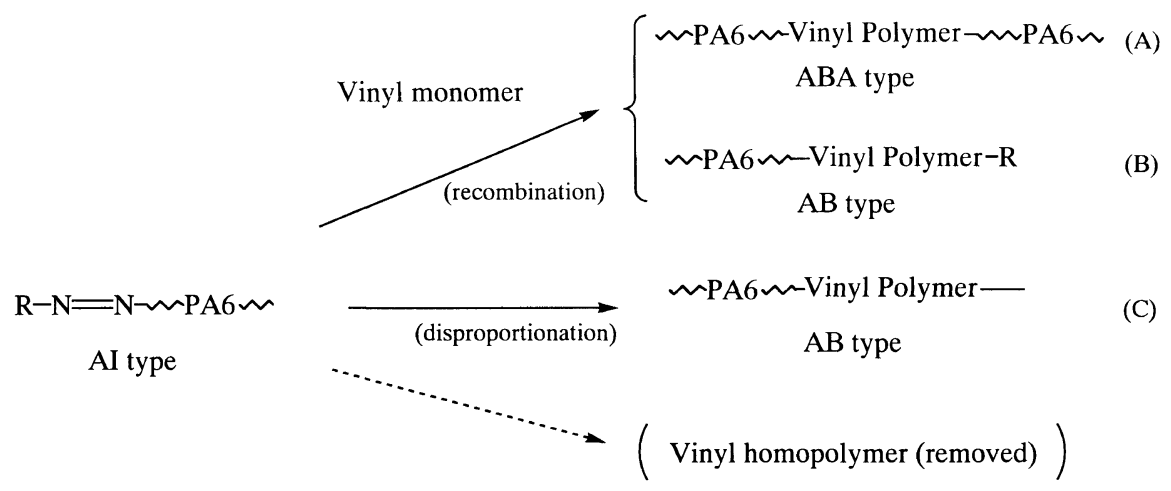

Scheme 2. Types of copolymers obtained from AI type PA6 radical initiators, when it is assumed that initiation efficiency is $100 \%$ and chain transfer reactions were negligible.

Table IV. Polymerization of vinyl monomers with Nylon 6 radical initiator at $60^{\circ} \mathrm{C}^{\mathrm{a}}$

\begin{tabular}{|c|c|c|c|c|c|c|c|c|c|c|}
\hline \multirow{3}{*}{ Run } & \multirow{3}{*}{$\begin{array}{c}\text { Vinyl } \\
\text { monomer }^{\mathbf{b}}\end{array}$} & \multicolumn{3}{|c|}{ Nylon 6 initiator } & \multirow{3}{*}{$\begin{array}{c}{[-\mathrm{N}=\mathrm{N}-] /} \\
{[\mathrm{Vinyl}]} \\
\times 10^{3}\end{array}$} & \multirow{3}{*}{$\frac{\text { Polym. solvent }^{\mathrm{d}}}{\mathrm{mL}}$} & \multirow{3}{*}{$\mathrm{mL}$} & \multirow{3}{*}{$\frac{\text { Yield }}{w t \%}$} & \multirow{2}{*}{$\begin{array}{l}\text { Vinyl polym. } \\
\text { content }^{\mathrm{c}}\end{array}$} & \multirow{3}{*}{ Remarks } \\
\hline & & \multirow{2}{*}{$\begin{array}{l}M_{n_{\mathrm{PA} 6}{ }^{\mathrm{c}}} \\
\times 10^{-3}\end{array}$} & \multirow{2}{*}{ Type } & \multirow[b]{2}{*}{$\mathrm{g}$} & & & & & & \\
\hline & & & & & & & & & $\mathrm{mol} \%$ & \\
\hline $\mathrm{S} 1$ & St & 5 & AI & 0.94 & 20 & $\mathrm{PhOH} / \mathrm{MeOH}$ & 5 & 66.3 & 43 & \\
\hline $\mathrm{S} 2$ & St & 5 & $\mathrm{AI}$ & 0.94 & 20 & $\mathrm{PhOH} / \mathrm{MeOH}$ & 20 & 68.2 & 17 & \\
\hline S3 & St & 13 & AI & 1.20 & 9 & $\mathrm{PhOH} / \mathrm{MeOH}$ & 20 & 33.6 & 7 & \\
\hline $\mathrm{S} 4$ & St & 13 & AI & 0.50 & 22 & TFE & 5 & 50.0 & 21 & Hetero. ${ }^{f}$ \\
\hline S5 & St & 13 & AI & 0.50 & 20 & Formic acid & 5 & 51.4 & 15 & Hetero. ${ }^{\mathrm{f}}$ \\
\hline $\mathrm{B} 1$ & BMA & 8 & $\mathrm{AI}$ & 0.53 & 20 & TFE & 5 & 56.9 & 21 & \\
\hline $\mathrm{B} 2$ & BMA & 13 & $\mathrm{AI}$ & 0.50 & 10 & Formic acid & 5 & 45.0 & 11 & Hetero. ${ }^{\mathrm{f}}$ \\
\hline $\mathrm{H} 1$ & HEMA & 8 & AI & 0.50 & 8 & TFE & 5 & 46.8 & 30 & \\
\hline $\mathrm{H} 2$ & HEMA & 8 & AI & 0.50 & 9 & Formic acid & 5 & 62.3 & 36 & \\
\hline V1 & VAc & 5 & $\mathrm{AI}$ & 0.96 & 17 & $\mathrm{PhOH} / \mathrm{MeOH}$ & 20 & 43.3 & 0 & \\
\hline V2 & VAc & 5 & AIA & 0.58 & 5 & TFE & 5 & 38.1 & 19 & \\
\hline V3 & VAc & $(\mathrm{A}$ & & 0.03 & 10 & $\mathrm{PhOH} / \mathrm{MeOH}$ & 20 & 7.6 & & $M_{n}=310^{\mathrm{g}}$ \\
\hline V4 & VAc & (A & & 0.33 & 100 & $\mathrm{PhOH} / \mathrm{MeOH}$ & 20 & 54.5 & & $M_{n}=340^{\mathrm{g}}$ \\
\hline
\end{tabular}

${ }^{a}$ Polymerization time, $24 \mathrm{~h} . \quad{ }^{\mathrm{b}} \mathrm{St}$, styrene; BMA, butyl methacrylate; HEMA, hydroxyethyl methacrylate; VAc, vinyl acetate. ${ }^{\mathrm{c}} M_{n}$ of original PA6. ${ }^{d} \mathrm{PhOH} / \mathrm{MeOH}$, phenol/methanol $\left(4_{\mathrm{vol}} / \mathbf{1}_{\mathrm{rol}}\right)$; TFE, 2,2,2-trifluoroethanol. ${ }^{\mathrm{c}}$ Amount of vinyl polymer in the product. BMA, HEMA, VAc, calculated from ${ }^{1} \mathrm{H}$ NMR data (solvent: $\mathrm{D}_{2} \mathrm{SO}_{4}$ ); St, calculated from elemental analysis ( $N$-analysis). ${ }^{\mathrm{f}}$ Precipitation of copolymer and vinyl homopolymer. ${ }^{\mathrm{g}}$ Determined by GPC using polystyrene as standard.

The number of MMA units in block copolymers, $N_{2}$, is estimated from molar ratio of MMA units, $c_{2}$, and $M_{n}$ of PA6 segments, $M_{n_{1}}$ :

$$
N_{2}=\frac{c_{2}}{\left(1-c_{2}\right)} \cdot \frac{M_{n_{1}} \cdot L_{1}}{m_{1}}
$$

where $m_{1}$ is the molecular weight of PA6 units. Thus, $M_{n}$ of poly(MMA) segments, $M_{n_{2}}$, is calculated as,

$$
M_{n_{2}}=\frac{N_{2}}{N_{p}} m_{2}=\frac{c_{2}}{\left(1-c_{2}\right)} \cdot \frac{4}{(3+p)} M_{n_{1}} \frac{m_{2}}{m_{1}}
$$

where $m_{2}$ is the molecular weight of an MMA unit. Then, overall initiation efficiency, $f_{\text {all }}$, is estimated by

$$
f_{\mathrm{all}}=\frac{M_{n_{\mathrm{calc}}}}{M_{n_{\mathrm{GPC}}}}
$$

where $M_{n_{\text {calc }}}$ is $M_{n}$ calculated by eq 5 and $M_{n_{\mathrm{GPC}}}$ is $M_{n}$ measured by GPC. $M_{n_{\text {calc }}}$ of PA6-block-poly(MMA) prepared in formic acid (Run M5) was $6 \times 10^{3}$ if the fraction of disproportionation is $0.6,{ }^{33}$ while $M_{n_{\mathrm{GPC}}}$ was $54 \times 10^{3}$. Thus, overall initiation efficiency was calculated

Polym. J., Vol. 31, No. 10, 1999

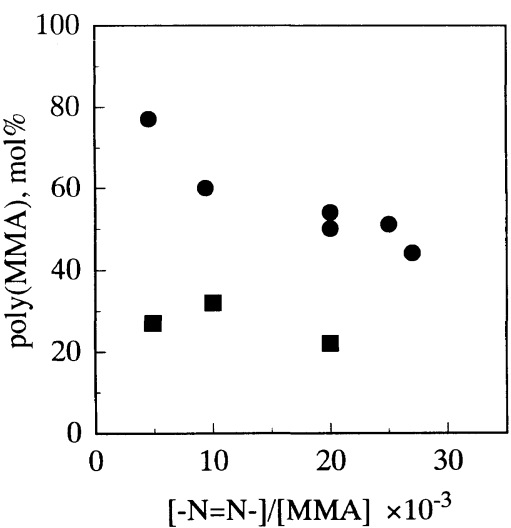

Figure 6. Effects of the concentrations of PA6ini, AI (-) and AIA (ם), on amount of poly(MMA) in the polymer synthesized using PA6ini.

0.11 by eq 6 . This agrees with overall initiation efficiency (0.15) of the MAI consisting of PA66 or PA610 in $m$-cresol, as reported by Ueda et al. ${ }^{24}$

Figure 6 shows the amounts of poly(MMA) incor- 
porated in the product to increase with decrease in azo groups. This is consistent with the results of synthesis of poly(MMA)-block-poly(St) with MAI consisting of poly $(\mathrm{St})$, as reported by Oppenheimer et al. ${ }^{34}$ The amounts of poly(MMA) decreased with increase of $M_{n}$ of PA6ini, as shown in Table III. The amounts of poly(MMA) in polymers prepared with AIA were less than those with AI under similar conditions. This may result from reduction in the rate of diffusion, as pointed out by George et al. for low initiation efficiency of MAIs based on bisphenol A and ACPC. ${ }^{35}$

Block Copolymers from PA6 and Vinyl Polymers. The results of synthesis of block copolymers based on PA6 and various vinyl polymers are shown in Table IV. In all runs, PA6inis did not precipitate by the addition of

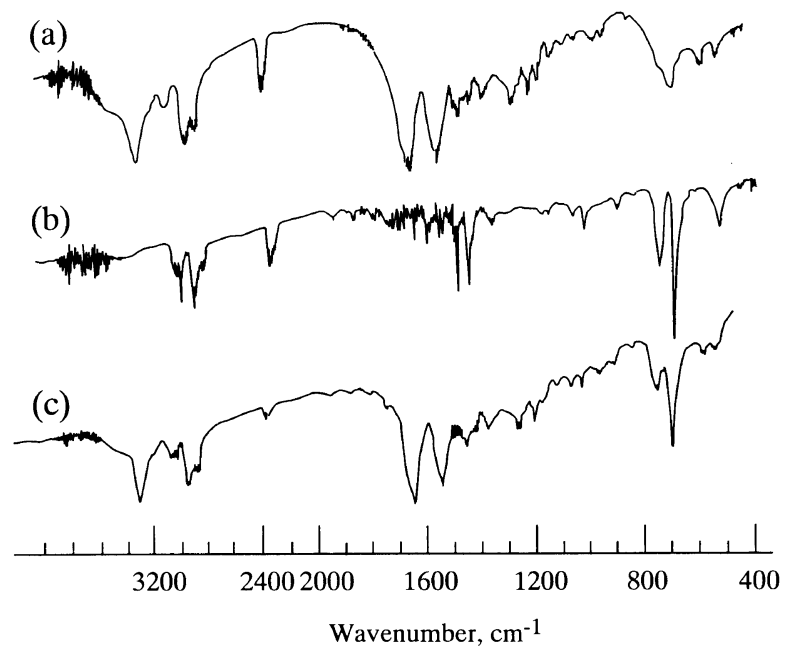

Figure 7. IR spectra of PA6 homopolymer (a), poly(St) homopolymer (b), and PA6-block-poly(St) (Run S1) (c). the vinyl monomer.

IR spectra of PA6-block-poly(St) (Run S1), PA6 and poly(St) are shown in Figure 7. The IR spectrum of PA6-block-poly(St) was comprised of absorptions of PA6 with poly(St). The radical polymerizations of St in TFE and formic acid (Run S4 and S6) proceeded heterogeneously because poly(St) and PA6-block-poly(St) were insoluble in these solvents. St in these PA6-block-poly $(\mathrm{St})$ was higher than that in PA6-block-poly(St) prepared in phenol/methanol (Run S3), whose polymerization proceeded homogeneously.

${ }^{1} \mathrm{H}$ NMR spectra of PA6-block-poly(BMA) (Run B1) and PA6-block-poly(HEMA) (Run H1) are shown in Figures $8(1)$ and $8(2)$. These spectra indicate that block copolymers were synthesized by the radical polymerization of BMA and HEMA with PA6ini as well as synthesis of PA6-block-poly(MMA).

PA6-block-poly(VAc) could not be synthesized in phenol/methanol $\left(4_{\mathrm{vol}} / \mathbf{1}_{\mathrm{vol}}\right)$, as shown in Table IV. $M_{n}$ of poly(VAc) prepared with ACPA as an initiator in phenol/methanol was very small. This may result from the high chain transfer constant of VAc to phenol $\left(600 \times 10^{-4}\right.$ at $\left.60^{\circ} \mathrm{C}\right)$ in contrast to that of $\mathrm{St}$ $\left(14 \times 10^{-4}\right) .{ }^{36}$ PA6-block-poly(VAc) (Run V2) could be synthesized in TFE. ${ }^{1} \mathrm{H}$ NMR spectrum of PA6-blockpoly(VAc) is shown in Figure 8(3). Signals based on poly(VAc) and PA6 were observed.

\section{CONCLUSIONS}

1. PA6ini, AI, and AIA, were synthesized by the condensation reaction of PA6 prepolymer with ACPC. $\mathrm{AI}$ and AIA were prepared in phenol/methanol $\left(4_{\mathrm{vol}} / 1_{\mathrm{vol}}\right)$ and phenol/benzene $\left(4_{\mathrm{vol}} / 1_{\mathrm{vol}}\right)$ or DMI (contain $10 \mathrm{wt} \%$ $\mathrm{LiCl}$ ), respectively, as verified by measurements of solution viscosity; $\eta_{\text {red }}$ s of AI was the same as for origi-

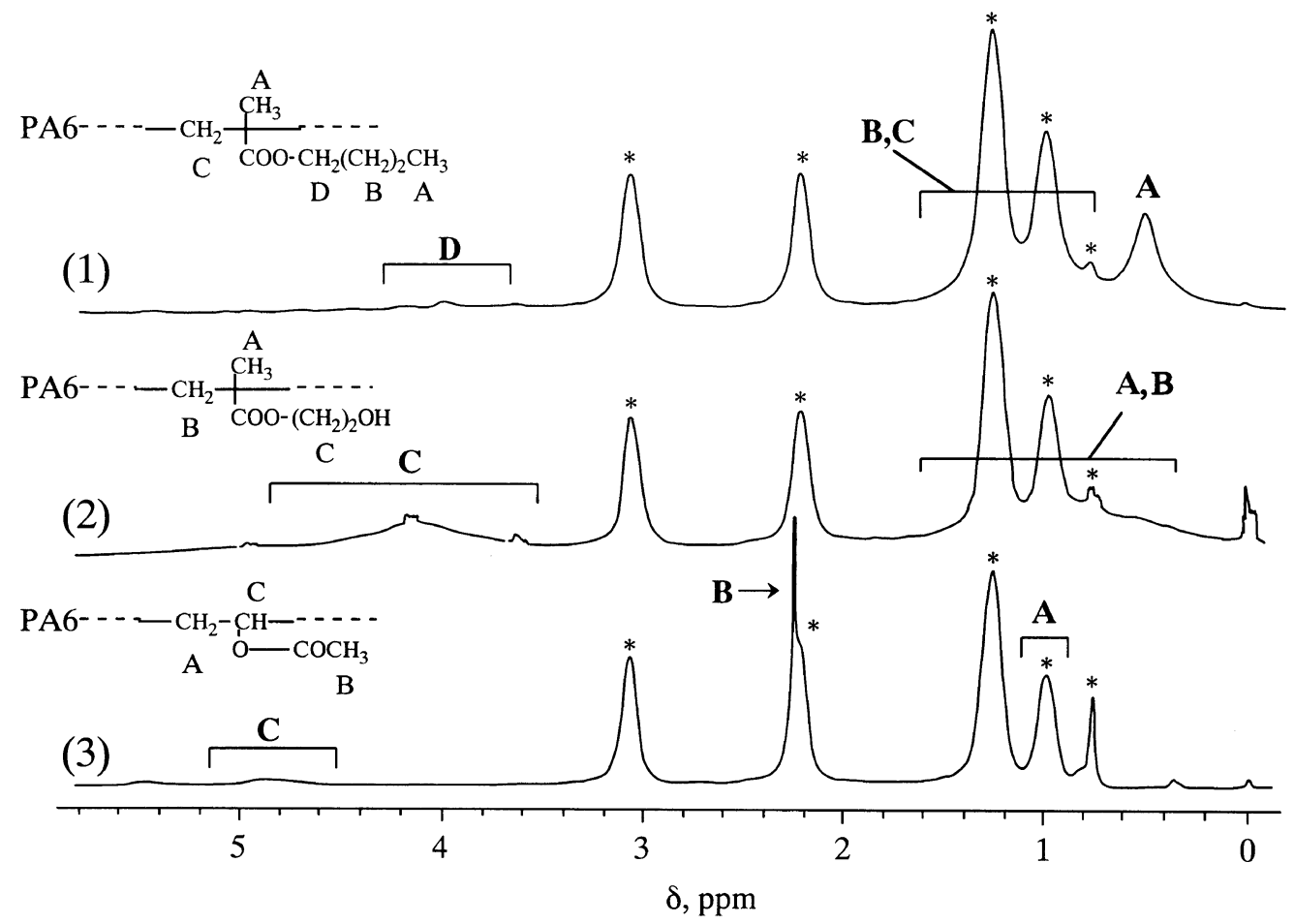

Figure 8. ${ }^{1} \mathrm{H}$ NMR spectra of PA6-block-poly(BMA) (Run B1) (1), PA6-block-poly(HEMA) (Run H1) (2), PA6-block-poly(VAc) (Run V2) (3), in $\mathrm{D}_{2} \mathrm{SO}_{4}$. ( *); Signals based on PA6 segment. 
nal PA6 homopolymers and AIA agreed with those of expected values calculated by eq 2 .

2. PA6-block-poly(MMA) were synthesized by the polymerizations of MMA with PA6inis in several solvents, such as phenol/methanol $\left(4_{\mathrm{vol}} / 1_{\mathrm{vol}}\right)$, formic acid and TFE. The polymerizations proceeded homogeneously. Initiation efficiency of PA6ini for the polymerization of MMA in formic acid was 0.11 . The amount of poly(MMA) in the polymer synthesized using PA6ini was dependent on concentration, molecular weight and type of PA6ini.

3. PA6-block-poly(St), PA6-block-poly(BMA), and PA6-block-poly(HEMA) were synthesized by the polymerizations of St, BMA, and HEMA with PA6inis in various solvents as well as syntheses of PA6-blockpoly(MMA). PA6-block-poly(VAc) was synthesized in TFE, but not in phenol/methanol.

4. The results of synthesis of various block copolymers with PA6inis showed that PA6inis are useful for the preparation of novel PA6-block-vinyl polymers.

\section{REFERENCES}

1. J. Stehliček, J. Horský, J. Roda, and A. Moucha, in "Lactam-Based Polyamides," Vol. 2, R. Puffr and V. Kubánek, Ed., CRC Press, Inc., Boca Raton, FL, 1991, p 20.

2. M. Sano, N. Yui, K. Sanui, N. Ogata, K. Kataoka, T. Okano, and Y. Sakurai, Kobunshi Ronbunshu, 42, 655 (1985).

3. N. Ogata and N. Yui, J. Macromol. Sci. Chem., A21, 1097 (1984).

4. S. Katayama, H. Serita, and Y. Takahashi, J. Polym. Sci., Polym. Chem. Ed., 15, 2109 (1977).

5. J. Stehlíček and J. Šebenda, Eur. Polym. J., 13, 949 (1977).

6. W. L. Hergenrother and R. J. Ambrose, J. Polym. Sci., Polym. Chem. Ed., 12, 2613 (1974).

7. Y. Shimura and N. Ikeda, J. Polym. Sci., Polym. Chem. Ed., 11, 1271 (1973)

8. M. V. Pandya, M. Subramaniyam, and M. R. Desai, Eur. Polym. J., 33, 789 (1997).

9. M.-S. Yn and C.-C. M. Ma, J. Appl. Polym. Sci., 53, 213 (1994).

10. J. Stehlíček, F Lednický, J. Baldrian, J. Šebenda, and E. Neuhausl, Polym. Eng. Sci., 31, 422 (1991).

11. V. Maroušek, P. Svoboda, and J. Králíček, Angew. Makromol. Chem., 178, 85 (1990)
12. W. T. Allen and D. E. Eaves, Angew. Makromol. Chem., 58/59, 321 (1977)

13. I. Cho and K.-W. Lee, Taehan Hwahak Hoechi, 20, 424 (1976); Chem . Abstr., 86, 73165t (1977).

14. V. Nováková, R. Sobotík, J. Matěnová, and J. Roda, Angew. Makromol. Chem., 237, 123 (1996).

15. K. A. H. Lindberg and H. E. Bertilsson, J. Mater. Sci., 26, 4383 (1991).

16. D. Petit, R. Jerome, and Ph. Teyssie, J. Polym. Sci., Polym. Chem. Ed., 17, 2903 (1979).

17. R. H. Wondraczek and J. P. Kennedy, J. Polym. Sci., Polym. Chem. Ed., 20, 173 (1982).

18. A. Ueda and S. Nagai, in "Macromolecular Design: Concept and Practice", M. K. Mishra, Ed., Polymer Frontiers International, Inc., New York, N.Y., 1994, p 265.

19. H. Craubner, J. Polym. Sci., Polym. Chem. Ed., 18, 2011 (1980).

20. H. Craubner, J. Polym. Sci., Polym. Chem. Ed., 20, 1935 (1982).

21. A. Ueda and S. Nagai, J. Adhes. Soc. Jpn., 26, 112 (1990).

22. O. Nuyken and B. Voit, in "Macromolecular Design: Concept and Practice," M. K. Mishra, Ed., Polymer Frontiers International, Inc., New York, N.Y., 1994, p 313.

23. A. Ueda, Y. Shiozu, Y. Hidaka, and S. Nagai, Koubunshi Ronbunshu, 33, 131 (1976).

24. A. Ueda and S. Nagai, J. Polym. Sci., Polym. Chem. Ed., 22, 1611 (1984)

25. A. Ueda and S. Nagai, J. Polym. Sci., Polym. Chem. Ed., 22, 1783 (1984)

26. M. Kamachi, in "Shin Koubunshi Jikkengaku 2; Koubunshi no Gousei · Hannou (1)," Kyoritsu Shuppan, Tokyo, 1995, p 15.

27. S. W. Seo, W. H. Jo, and W. S. Ha, J. Appl. Polym. Sci., 29, 567 (1984).

28. J. J. Laverty and Z. G. Gardlund, J. Polym. Sci., Polym. Chem. Ed., 15, 2001 (1977).

29. N.Ogata, Kogyo Kagaku Zasshi, 73, 2279 (1970).

30. T. Hirano, K. Onimura, H. Tsutsumi, and T. Oishi, Polym. J., in press.

31. H. Inoue, A. Ueda, and S. Nagai, J. Polym. Sci., Part A, Polym. Chem., 26, 1077 (1988).

32. N. Hashimoto, T. Aoyama, and T. Shioiri, Chem. Pharm. Bull., 29, 1475 (1981)

33. Von G. V. Schulz, G. Henrici-Olivé, and S. Olivé, Makromol. Chem., 31, 88 (1959).

34. C. Oppenheimer and W. Heitz, Angew. Makromol. Chem., 98, 167 (1981).

35. M. H. George and J. R. Ward, J. Polym. Sci., Polym. Chem. Ed., 11, 2909 (1973)

36. K. C. Berger and G. Brandrup, in "Polymer Handbook," 3rd ed, J. Brandrup and E. H. Immergut, Ed., John Wiley \& Sons, New York, N.Y., 1989, p II/81. 